\title{
Separate Consent for Anesthetic Practice: Need of the Moment
}

\author{
Anil Shrestha, Gentle S Shrestha, Saurabh Pradhan, Pankaj Joshi \\ Department of Anesthesiology, Maharajgunj Medical Campus, Tribhuvan University Teaching Hospital, Institute \\ of Medicine, Maharajgunj, Kathmandu, Nepal
}

\section{Corresponding author:}

\section{Gentle S Shrestha, MBBS, MD}

Department of Anesthesiology, Maharajgunj Medical Campus, Tribhuvan University Teaching Hospital, Institute of Medicine, Maharajgunj, Kathmandu, Nepal

Email:gentlesunder@hotmail.com

Submitted : Nov 11, 2020

Accepted : Dec 15, 2020

\begin{abstract}
Decades of refinement and modifications have led the modern anaesthetic practice to be conducted so smoothly and safely, that sometimes we take for granted the enormous amount of risks involved with it. Furthermore, with the evolution of monitoring techniques, and discovery of safer drugs, anesthesia has facilitated the conduction of complex surgeries on sicker patients, and older patients. The expansion to critical care and pain management services has added another dimension to this field, with anesthesiologists not just working as facilitators for another procedure, but acting as primary physicians. Anesthesiologists are among the few clinicians, who are involved in patient morbidity and mortality in their daily routine. With the ever-changing ethical and legal background, the significance of obtaining a separate consent for anesthesia needs to be timely evaluated. In this review, we have discussed the significance of a separate consent for anesthesia and highlight its various aspects.
\end{abstract}

Keywords

Anesthetic practice, separate consent

\section{INTRODUCTION}

$\mathrm{n}$ modern day medical practice, the number of surgeries carried out every year is increasing. With the increase of surgical cases patient receiving anesthesia services is also increasing. There are estimated 230 million anesthetic procedures performed worldwide annually. ${ }^{1}$ Anesthesiologists are not only involved in providing anesthesia for surgery but also largely involved in intensive care and pain management services.

Modern anesthesia is very safe, with an average attributable mortality of less than $1: 10,000^{2}$ and as low as 1:100 000 in the UK. ${ }^{3}$ The estimated rates from anesthesia-related deaths were 1.1 per million population per year and 8.2 per million hospital surgical discharges in the United States. ${ }^{4}$ Data from developing countries, including Nepal, are sparse, but a similar decline in anesthesia related morbidity and mortality can be appreciated. As a result of the success of anesthesia, it has become a challenge to itself, with surgeons not hesitating to perform very complex surgeries even in much sicker patients. It has resulted in more clinically and technically challenging anesthetic practice. Though safe, the risk associated with anesthesia should not be undermined. It can and has led to multiple complications, ranging from relatively minor to fatal outcomes, which poses both ethical and legal consequences. Anesthesiologists should be aware of the different frameworks that apply in relation to consent and special circumstances encountered during their practice. 
With increasing patient awareness regarding surgical and anesthetic practice due to the availability of information in the internet, increasing concern about the right to information and a surge in closed claims of medical negligence the need for a well informed consent is now very justified.

\section{ETHICAL, PROFESSIONAL AND LEGAL ASPECTS}

The concept of medical consumerism has been adopted from the western society. Such a theology considers the patient a consumer, who dictates the provision of services rather than the healthcare provider. In other words, principle of autonomy, an integral part of medical ethics, governs modern medicine. The moral foundations of autonomy are mainly reflected in the requirement to obtain informed consent, which is considered a permission for something to happen or an agreement to do something.

Obtaining a consent prior to performing any procedure, is thus an ethical obligation, and it is central to the doctor-patient relationship. However, consent for anesthesia has traditionally been considered as "implied" once the patient consents to surgery ${ }^{5}$ and often included within the surgical consent, if even included. So commonly, a member of the surgical team would be involved in obtaining the consent for anesthesia, and considering the lack of training to formulate an anesthetic plan, that would be inappropriate. The risks associated with anesthesia are independent of the surgery and may be much greater than that associated with the surgery. A separate consent would provide the anesthesiologist with the responsibility of making the patient clearly understand the anesthetic technique, its benefits and risks, and alternatives if available. Understanding the nature and purpose of the anesthetic intervention, also empowers the patient to have a greater involvement in decision making regarding their health care. This eventually leads to better patient satisfaction, ${ }^{6}$ an integral part of our professional goal.

Performing procedures without consent does not only have ethical and professional obligations, but also legal consequences. Even touching a patient without consent can lead to claims of assault or battery. However, much more common, is the claim of negligence when complications occasionally do occur. There is a growing threat of litigation, and anesthesiologists are not at all spared. Having a separate consent allows accurate documentation of the process, which may help in cases of litigation. However, more importantly, a separate consent taken by the anesthesiologist after sufficient discussion about the proposed anesthetic technique and inherent risks, reduces the threat of litigation itself. ${ }^{7}$

\section{ELEMENTS OF A VALID INFORMED CONSENT}

\section{Timing}

Information about anesthesia and its associated risks should be provided to patients as early as possible. It takes time to explain anesthesia to patients, and time for them to reflect on this information and ask further questions. Therefore taking an informed consent should not be done under haste. For example, immediately before induction of anesthesia is not an acceptable time to provide elective patients with new information. Thus those undergoing elective surgery should be provided with information before admission, preferably at pre-anesthetic checkup. At the end of the discussion, they should be asked whether they have any questions and the details of the discussion recorded. Consent is an ongoing process, and so repeated discussion and documentations may be required.

\section{Capacity, best interest and voluntariness}

For a consent to be legally valid, it must have three requirements. The individual 1) should be competent to decide; 2) be given proper information on which to base that decision; and 3) be allowed to make the decision voluntarily, without any force or coercion. All adults (16 year or older) should be presumed to have capacity to consent. ${ }^{8}$ In case of pediatric patient, parents are the decision maker and can give the consent. In absence of any of the parents the legal guardian appointed by the parents or the court can act as a decision maker.

There are four recognized and legally validated components to decision-making capacity in an adult. The patient must understand the known risks and benefits of the treatment and its alternatives; the patient must be able to appreciate his or her clinical situation relative to the proposed treatment plan; the patient must be able to formulate a plan independently; and the patient must be able to appropriately communicate his or her decision and ask or answer questions related with the decision. ${ }^{9}$ There are circumstances in which even competent patients may insist they do not want to know about the risks of the anesthetic procedure or opt for decisions that are not at their best interest. However in medical ethics, autonomy of the patient is always considered over best interest. In such a case, the consequences should be explained and the discussion recorded. The autonomy of the patient needs to be respected. Giving the power to the patient to choose, agree upon or disagree the medical management provided to them without any unwarranted interference from other also improves patient satisfaction and yields more favorable medical outcome. ${ }^{10}$

The issue of voluntariness is often more important in anesthesia. The voluntariness of the consent 
for anesthesia is called into question as in many instances anesthesia being a condition precedent to surgery, the patients do not have much choice. However it was found that patients consent to undergo surgery but it is often the anesthetic that frightens them. ${ }^{11}$ In such cases information regarding anesthesia and separate consent for anesthesia becomes more valid.

Adult patients may lack capacity, due to cognitive or psychiatric disorders. A clear record of the grounds on which practitioners have reached this conclusion should be made. Interestingly, two case reports by Marcucci et al. suggested that the capacity to give surgical consent does not imply having the capacity to give anesthetic consent. ${ }^{12}$ The cognitive demands of anesthesia and surgery seem to be different, with surgery being a more tangible process and the concept of consciousness, awareness and memory, aspects inherently involved with anesthesia, rather abstract. So patients with subclinical cognitive deficiencies may not understand anesthesia even if they understand surgery.

In patients who are considered to lack capacity to consent, a surrogate decision maker can be allowed to make decisions on his/her behalf. Such a substitute is usually a close relative of the patient, however the legal status of surrogates varies from country to country. The surrogate may make decisions for the patient using substituted judgment, which considers what the patient would have made if he or she were able to make decisions, based on their knowledge of the patient. When no specific information is available about a patient, apply a "reasonable-person" standard-that is, what a reasonable person would prefer in the clinical situation at hand-and sometimes resort to a "best-interest" standard. ${ }^{13}$

Occasionally, competent adults may give an "advance directive", in which the patient determines what kind of care he or she would want in the setting of some anticipated situation in advance and makes known his or her wishes regarding future medical care in case they lose the capacity to consent. ${ }^{13}$

\section{INFORMATION TO BE PROVIDED}

The important duty of the anesthesiologist is to provide complete information to the patient regarding the procedure. From legal point of view, full information should be disclosed to the patient. ${ }^{14}$ However it is practically not possible as the patient will be burdened with whole information and would not be able to decide properly. ${ }^{15}$ What information would be appropriate to be provided for patients during the consenting process is challenging. The amount and the nature of information that should be disclosed to the patient should as far as possible be determined by the question: What would this particular patient regard as relevant when coming to a decision about which - if any - of the available options to accept? ${ }^{16}$ The depth of information should vary with the level of risk involved. ${ }^{17}$

Common components of anesthetic technique that needs to be informed to the patients include information regarding fasting, administration and effects of premedication, transfer from ward to anesthetic room, intravenous cannula insertion, non-invasive monitoring, induction of general anesthesia and/or administration of local anesthetic, endotracheal intubation, monitoring throughout surgery by the anesthesiologist, administration of intra-operative drugs/fluids, extubation and transfer to recovery area. Alternative techniques, where appropriate, should also be discussed. For example providing general anesthesia for cesarean section as an alternative to regional anesthesia, or when the latter is inadequate should also be mentioned.

Specific aspects related to the procedure other than the usual practice may be highlighted. These may include the use of invasive monitoring and associated risks, recovery in a critical care environment, anticipated difficult intubation or probable tracheotomy, intra-operative discomfort or awareness of the procedure and/or surroundings.

Common and significant side-effects like nausea and vomiting, sore throat, damage to teeth/lips, cognitive dysfunction, numbness/weakness/return of pain after local anesthetic techniques, succinylcholine induced pain and post-dural puncture headache should be informed to the patient. Complications related to the patients general condition and comorbidities and possible consequences also need to be explained to the patient. Occasionally the condition of the patient and the surgery may warrant discussion of some serious side-effects such as nerve or eye damage and even death. An example of consent for anesthetic practice is included in Figure 1. The sample consent can be modified based on institutional policy and special clinical circumstances.

\section{SPECIAL CIRCUMSTANCES}

Apart from medical conditions that incapacitate an individual to reason and give informed consent, there are certain instances specific to anesthetic practice, where despite the person being mentally sound, the situation may hinder competency of the individual. Anesthesiologists also encounter situations, where the usual process of consent may be different than in general population.

\section{Premedication}

Patients undergoing surgery are frequently provided with premedications such as benzodiazepines or opioids prior to surgery. These medications may cause certain degree of sedation, which could impede the capacity of decision-making. Therefore 


\section{INFORMED CONSENT}

\section{Authorization for Administration of Anesthesia/Sedation}

I/my patient.

(name of the patient) have/ has to undergo

(name of Surgery/Procedure) for which Anesthesia/ Sedation services are required. I hereby consent to the anesthesia / sedation service checked below and authorize that it can be administered by Anesthesiologist who are credentialed to provide anesthesia or sedation services.

\begin{tabular}{|c|c|c|}
\hline \multirow[t]{3}{*}{ General Anesthesia } & Benefits & $\begin{array}{l}\text { - Complete control of airway, breathing and circulation } \\
\text { - Allows complete stillness during the procedure } \\
\text { - Permits surgery in widely separated areas of the body at the same time }\end{array}$ \\
\hline & Technique & $\begin{array}{l}\text { - Drug injected into bloodstream, breathed into lungs, or by other routes } \\
\text { - Airway devices (endotracheal tube or supraglottic airways) inserted to secure airway. }\end{array}$ \\
\hline & Risks & $\begin{array}{l}\text { - Mouth or throat pain, hoarseness, injury to mouth, lips, vocal cords, eyes or teeth } \\
\text { awareness under anesthesia, injury to blood vessels, aspiration, pneumonia, cardiovascula } \\
\text { instabilities like arrythmias, hypo/hypertension, myocardial ischemia/infarction, permanen } \\
\text { organ damage, brain damage. } \\
\text { - Weakness, numbness in the limbs, paresthesia }\end{array}$ \\
\hline \multirow{3}{*}{$\begin{array}{l}\text { Spinal or Epidural } \\
\text { Analgesia/Anesthesia } \\
\text { - With sedation } \\
\text { - Without sedation }\end{array}$} & Benefits & $\begin{array}{l}\text { - Early postoperative mobilization } \\
\text { - Reduced postoperative pulmonary, thromboembolic and cardiac complication }\end{array}$ \\
\hline & Technique & $\begin{array}{l}\text { - Drug injected through a needle/catheter placed either directly into spinal canal o } \\
\text { immediately outside the spinal canal }\end{array}$ \\
\hline & Risks & $\begin{array}{l}\text { - Headache, backache, convulsions, infection, persistent weakness, numbness, residua } \\
\text { pain, injury to blood vessel, spinal or epidural hematoma } \\
\text { - May require conversion to general anesthesia. }\end{array}$ \\
\hline \multirow[t]{3}{*}{$\begin{array}{l}\text { Major/Minor Nerve Block } \\
\text { Anesthesia } \\
\text { - With sedation } \\
\text { - Without sedation }\end{array}$} & Benefits & $\begin{array}{l}\text { - Patient can remain awake } \\
\text { - Side effects like nausea and vomiting are avoidable } \\
\text { - Better pain relief } \\
\text { - No need for tracheal intubation }\end{array}$ \\
\hline & Risks & $\begin{array}{l}\text { - Drug injected near nerves with/without the use of ultrasonography providing loss } 0 \\
\text { sensation to the area of operation. }\end{array}$ \\
\hline & & $\begin{array}{l}\text { - Infection, convulsion, persistent numbness, residual pain, injury to blood vessels, hematome } \\
\text { - May require conversion to general anesthesia. }\end{array}$ \\
\hline \multirow[t]{3}{*}{$\begin{array}{l}\text { Monitored Anesthesia Care } \\
\text { (with sedation) }\end{array}$} & Benefits & $\begin{array}{l}\text { - Optimal sedation, control of patient anxiety and pain } \\
\text { - Protection of airway }\end{array}$ \\
\hline & Technique & $\begin{array}{l}\text { - Drug injected into the bloodstream, breathed into lungs, or by other routes producing a } \\
\text { semi-conscious state. }\end{array}$ \\
\hline & Risks & $\begin{array}{l}\text { - An unconscious state, depressed breathing, permanent organ and/or brain damage } \\
\text { - May require conversion to general anesthesia. }\end{array}$ \\
\hline
\end{tabular}

I have been explained in a language that I understand the procedure involved in the administration of various types of anesthesia, together with the expected benefits and the associated risks including the risks that are specific to me/ my patient. If there is a problem, I/ my patient may have to be kept in a ventilator. Unexpected deaths are very rare but I understand that there is a possibility of death due to surgery or anesthesia.

There is a possibility of allergic reaction due to any medicine during the treatment and sometimes it can be life threatening. If I am already aware of such an allergy, I will inform the concerned doctor. I have been explained the risks associated with undergoing/ not undergoing blood transfusion and am willing/ not willing to undergo transfusion if required during perioperative period (if applicable). In the course of treatment / surgery, for the purpose of any medical, scientific or reading purpose, I would like to give permission of using my photo or some documents about the disease or surgery without revealing my identity.

During the process of my treatment/ surgery, if there is complications/ death of the patient, I will not take any legal actions or compensation against the hospital or any medical workers. I give consent to operate on any part of me / my patient's body by making me/my patient completely unconscious or anesthetizing some part of body.

I acknowledge that I have read this form or had it read to me and that I had ample time to ask questions and to consider my decision.

Name of the patient

Name of Anesthesiologist /Physician

Name of the Witness

Name of the Guardian

Relationship to patient
Signature _................. Date and Time

Signature …. Date and Time

Signature .................. Date and Time

Signature Date and Time 
it may sometimes be difficult to judge the capacity of the patient after premedication. Obtaining consent earlier would avoid such situations.

\section{Chronic pain management}

The knowledge and skills acquired by an anesthesiologist have extended their role from perioperative physicians to pain medicine, which has become an integral part of their training and clinical practice. Anesthesiologists commonly manage patients with chronic pain with an armamentarium of techniques that range from simple analgesics to invasive procedures. Patients who seek therapy for chronic pain, may be so debilitated with their illness, that they will also consent to any analgesic intervention. In such cases, various intervention techniques to manage chronic pain needs to be discussed. Multiple session of interventions may be required is some cases. Detail of the proposed plan should be discussed before initiating it and consent can be obtained for full treatment course rather than taking it at every visit.

\section{Obstetric patient}

Women who are experiencing labour, may be having pain of such a degree that it could erode the capacity of the parturient to reflect on the information provided to her and make a sound decision based on it. She may be accepting any form of analgesia, without considering or being unable to understand the inherent risks associated with the anesthetic interventions that could be provided to her as a part of labour analgesia.

\section{Critical care}

Anesthesiologists are also involved in the treatment of patients in the intensive care unit (ICU), in coordination with other physicians or even as sole primary physicians, or intensivists. The process of consent is often more complicated in the ICU as mechanical ventilation, sedation, or critical illness itself incapacitates patients from rational decision making. The role of a surrogate decision maker becomes important, and sometimes extensive discussions are warranted to make decisions regarding medical care applying the principles either best interest or substituted judgment. Advance directives, such as Do Not Intubate (DNI), or Do Not Resuscitate (DNR) are also common. These wishes should be respected and followed accordingly. In emergency situations, when there may not be any time for obtaining an informed consent, management may be initiated within the principle of best interest.

\section{Jehovah's Witness}

Some patients due to their religious or other personal beliefs may refuse specific aspects of treatment. Jehovah's Witness are a distinct religious body within Christianity, who do not accept homologous blood transfusion, even if it is life-saving. When these patients come for anesthesia, their wishes must be respected. A record should be made indicating that the patient has been informed of the likely consequences. Various options to reduce blood loss, as well as the use of synthetic colloid solution, erythropoietin, and autologous blood transfusion must be discussed. ${ }^{18}$

\section{GLOBAL PERSPECTIVE AND THE CURRENT SCENARIO OF NEPAL}

Obtaining a separate consent for anesthesia is an emerging issue worldwide. Many countries have now mandated a separate consent and some are in the process. However, documentation of consent may not be recognized as sufficient evidence that valid consent has been obtained. ${ }^{19} \mathrm{~A}$ separate consent for anesthesia is a legal requirement in all states of the USA and the consent form is treated as presumptively valid consent. ${ }^{20}$ The Canadian Anesthesiologists Society do not explicitly advise that consent to anesthesia should be documented, but state that the pre-operative evaluation, which includes the consent process, should be documented. ${ }^{21}$ The Australian Law Reform Commission emphasizes that signature on a consent form may be substantial evidence that the patient consented, but it is not conclusive. ${ }^{22}$ The Association of Anesthetists of Great Britain and Ireland in its publication on Consent for Anesthesia recommends having a clear discussion with the patient about the risks and benefits, however, a separate anesthesia consent form has not yet been mandated. ${ }^{23}$ In Nepal, the Nepal Medical Council code of ethics and professional conduct recommend obtaining written informed consent before any invasive procedures, new treatments or additional treatments within the originally consented treatment plans when the additional treatment or intervention carry significant risks. ${ }^{24}$ However, clear directions regarding obtaining consent while providing anesthesia services is lacking. With the rising trend of medical litigations and growing mistrust between patients and the doctors, ${ }^{25}$ it is the need of the moment to practice proper communication with the patient and family and to consistently obtain separate consent for anesthetic practice. Large institutes and major academic centers may lead the exemplary initiatives, which then can be gradually generalized to other centers across the nation. Awareness campaigns and survey among the health care workers regarding the perception of need for separate consent during anesthetic practice can be imperative.

\section{CONCLUSION}

Anesthesiologists have long been engaged in the battle to be recognized as skilled professionals whose scope of practice is far different from 
that of surgeons. Anesthesiology is a separate entity and providing anesthesia and its aligned services should be considered a separate medical intervention with separate medical risks. The use of a separate informed consent would empower our patients to have a greater involvement in decision making and engage our patients as partners in their anesthetic delivery to ensure the best outcome as well as improved satisfaction. Compared to surgery, a higher cognitive capacity is also required to understand the abstract concept of anesthesia. Therefore, no medical personnel other than the anesthesologist can justify it. Anesthesiologists need to do this to ensure that the patient is fully informed of the process, risks, benefits, and alternatives. The evolving ethical, professional and legal provisions mandate a separate consent and special circumstances encountered by anesthesiologists need unique attention. Leadership from the national bodies and collaboration between the related organizations (national anesthesiology society, national medical council, different surgical societies and legal bodies) will be necessary to help achieve the goals.

\section{CONFLICT OF INTEREST}

None declared.

\section{REFERENCES}

1. Schiff JH, Wagner S. Anesthesia related mortality? A national and international overview. Trends in Anaesthesia and Critical Care. 2016;9:43-8

2. Braz LG, Braz DG, Cruz DS et al. Mortality in anesthesia: a systematic review. Clinics (Sao Paulo). 2009;64(10):999-1006.

3. Buck N, Devlin HB, Lunn JN, eds. The Report of the Confidential Enquiry into Perioperative Deaths (1987).London, the Nuffield Provincial Hospitals Trust/King's Fund 1987

4. Li G, Warner M, Lang BH et al. Epidemiology of anesthesiarelated mortality in the United States, 1999-2005. Anesthesiology. 2009;110(4):759-65.

5. Singh TSS. Is it time to separate consent for anesthesia from consent for surgery?. J Anaesthesiol Clin Pharmacol. 2017;33(1):112-3.

6. Rampersad K, Chen D, Hariharan S. Efficacy of a separate informed consent for anesthesia services: A prospective study from the Caribbean. J Anaesthesiol Clin Pharmacol. 2016;32:18-24.

7. Levinson $W$, Roter DL, Mullooly JP et al. Physician-patient communication. The relationship with malpractice claims among primary care physicians and surgeons. JAMA. 1997;277:553-9.

8. Nepal Medical Council. NMC-Code of Ethics. [Internet]Available from https://www.nmc.org.np/23

9. Appelbaum PS, Grisso T. Assessing patients' capacities to consent to treatment. N Engl J Med. 1988;319:1635-8.

10. Waisel DB, Truog RD. The benefits of the explanation of the risks of anesthesia in the day surgery patient. Journal of Clinical Anesthesia. 1995;7(3):200-4.

11. Leigh JM, Walker J. Effect of preoperative anaesthetic visit on anxiety. BMJ 1977;2:987-9.

12. Marcucci C, Seagull FJ, Loreck D et al. Capacity to give surgical consent does not imply capacity to give anesthesia consent: Implications for anesthesiologists. Anesth Analg. 2010;110:596600.

13. Bledsoe TA, Levy MM. Basic Ethical Principles in Critical Care. In: Vincent JL, Abraham E, Moore FA, Kochanek PM, Fink MP, editors. Textbook of critical care. 6th ed. New Delhi. Elsevier. 2011. p. 1573-75

14. Maclean A. From sidaway to pearce and beyond: is the legal regulation of consent any better following a quarter of a century of judicial scrutiny? Medical Law Review. 2012; 20 (1):108-29

15. Lynöe N, Hoeyer K. Quantitative aspects of informed consent: considering the dose response curve when estimating quantity of information. Journal of Medical Ethics 2005;31:736-38.

16. Department of Health. Reference guide to consent for examination or treatment. London: DoH, 2009. https://www. gov.uk/government/uploads/system/uploads/attachment_data/ file/138296/dh_103653____.pdf

17. Gagandeepa K, Neerub B, Pala AJ et al. Consent for anesthesia. Ain Shams Journal of Anesthesiology. 2016;9(1):6-11.

18. Benson KT. The Jehovah's Witness patient: considerations for the anesthesiologist. Anesth Analg 1989;69:647-656.

19. Faunce TA. Medical disclosure and consent forms: proposalfor an international standard. Medicine and Law.1997;16:581-91.

20. O'Leary CE. Informed consent for anesthesia: Has the time come for a separate written consent document? ASA Newsl. 2006;70:11-2.

21. Canadian Anesthesiologists' Society. Guidelines to the Practice of Anaesthesia. The Preanaesthetic Period. http://www.cas.cal guidelines/pre_an.asp

22. Law Reform Commission of Victoria. Report 24. InformedDecisions About Medical Procedures.http://www.austlii.edu.au/au/other/alrc/ publications/reports/50/chap1.pdf

23. Yentis SM, Hartle AJ, Barker IR et al. AAGBI: Consent for anaesthesia 2017. Anaesthesia. 2017; 72: 93-105.

24. Nepal Medical Council. Code of ethics and professional conduct-2017. [Internet]Available from https://nmc.org.np/files/4/ Code\%20of\%20Ethics_Print_version.pdf

25. Shrestha R. Medical negligence: an insight. Kathmandu Univ Med J (KUMJ). 2008;6(24):533-4. 